\title{
Oncolytic Viruses in Tumor Therapy: The Russian Perspective
}

\author{
Nadezhda M. Kolyasnikova ${ }^{1}$, Nikolay B. Pestov ${ }^{1,2,3}$, Jeanne M. Sanchez-Pimentel ${ }^{1}$, Nikolay A. Barlev ${ }^{1,2,4, *}$ and Aidar \\ A. Ishmukhametov ${ }^{1}$ \\ 1 Chumakov Federal Scientific Center for Research and Development of Immune-and-Biological Products of \\ Russian Academy of Sciences, Laboratory of Tick-Borne Encephalitis and Other Viral Encephalitides, \\ Poselok Instituta Poliomielita 8 bd 17, Poselenie Moskovsky, Moscow, 108819, Russia \\ 2 Moscow Institute of Physics and Technology, Phystech School of Biological and Medical Physics, \\ Laboratory of Molecular Oncology, 9 Institutskiy per., Dolgoprudny, Moscow Region, 141701, Russia \\ 3 Shemyakin-Ovchinnikov Institute of Bioorganic Chemistry, Group of Cross-Linking Enzymes, Miklukho- \\ Maklaya 16/10, Moscow, 117997, Russia \\ 4 Orekhovich Institute of Biomedical Chemistry, Moscow, Russia \\ * Correspondence: nick.a.barlev@gmail.com; Tel.: +79117022188
}

\begin{abstract}
The idea of using the lytic power of viruses against the malignant cells has been entertained for many decades. However, oncolytic viruses (OV) gained broad attention as an emerging anti-cancer therapy only recently with the successful implementation of the oncolytic herpesvirus to treat advanced melanoma. OVs offer an attractive therapeutic combination of tumorspecific cell lysis together with immune stimulation, yet the latter effect is less well studied. Nevertheless, OVs can be envisaged as potential in situ tumor vaccines. The therapeutic potential of OVs can be instigated further by using the molecular biological and biotechnological tools to modify the existing viruses for their optimal tumor selectivity and enhanced immune stimulation. Furthermore, OVs can be readily combined with other therapeutic agents to increase the efficacy of the existing therapeutic schemes. In this review, we discuss biotechnological advances in the development of therapeutic applications of OVs in Russia. Particular emphasis is made on the OVmediated treatment of glioblastoma. In addition, we highlight the challenges of oncolytic virotherapy, and describe the strategies to optimize current approaches to improve clinical outcomes.
\end{abstract}

Keywords: virotherapy, oncolytic viruses, gliomas, pancreatic cancer, adenoviruses, parvoviruses, enteroviruses, blood-brain barrier, tropism, transgene.

\section{Introduction}

Oncolytic virotherapy has received a powerful impetus in recent years thanks to the limited but encouraging success of clinical trials in Latvia [1], China [2], and the USA [3]. This led to the revitalization of the research on oncolytic viruses (OVs) in Russia and commencement of new approaches to address inherent problems of biosafety and their efficacy against solid tumors.

\section{History of Studies on OVs in the former USSR and Russian Federation}

The first records of anticancer activity conferred by viral infection are dated back to the 19th century and, at that time, the evidences were somewhat anecdotal (reviewed in [4]). For example, in 1904 Dr. George Dock published a report about a leukemia patient who experienced a decreased leukocyte count after a naturally occurring infection with influenza [5]. Further, an Italian doctor de Pace described a case of curing a patient with 
cervical cancer during a course of anti-rabies vaccinations after a dog bite [6]. In 1949, the Russian Far East Virus was observed to inhibit the growth of tumors transplanted into mice [6]. Since then, considerable efforts have been spent around the world on the elucidation of the molecular mechanisms for oncotropism and the oncolytic action of various viruses. Significant oncolytic effects were observed for a number of neurotropic viruses: tick-borne encephalitis (Far Eastern variant), Scottish sheep encephalomyelitis, Omsk hemorrhagic fever, Langat and others (tick-borne encephalitis complex viruses). Since the early 40 s of the last century, this avenue of research has been actively pursued by a number of research groups. R. Shen [7] and A. Moore [8] have shown that viruses exhibited a significant oncotropism towards tumors found in experimental animals in vivo, thereby inhibiting the growth of tumor cells. E.N. Levkovich and L.G. Karpovich (Laboratory of Tick-Borne Encephalitis IPVE, Institute of Poliomyelitis and Viral Encephalitis, Moscow, USSR) studied 25 strains of the tick-borne encephalitis virus (TBE) and related strains of viruses (Scottish sheep encephalomyelitis, Omsk hemorrhagic fever, Kyasanur forest fever etc) and found that these viruses actively reproduced in HeLa cells, however, their cytopathogenic effects varied greatly [9]. In the next cycle of works, E.N. Levkovich and G.I. Sergeeva showed an inhibitory effect of all strains of the TBE complex viruses on the growth of Ehrlich's ascites carcinoma and Crocker's sarcoma in vitro. The TBE and Langat viruses were found capable of infecting tumor cells with subsequent reduction of their proliferative ability, as well as the delayed growth when transplanted into experimental animals $[10,11]$. Despite the initial success, clinical studies on the overall safety and efficacy of these OVs were never attempted due to the unresolved problems of their high pathogenicity.

The idea of employing enteroviruses for virotherapy has emerged in the 1950s and was based on the observation that enteroviruses can actively multiply and destroy various tumor cell lines, including HeLa cells. This approach looked safe thanks to the development of very efficient live attenuated poliomyelitis and other enterovirus vaccines. Experimental and clinical studies conducted under the supervision of the Academy of Medical Sciences and the Ministry of Health of the USSR in Moscow and Riga revealed oncotropic and oncolytic activities of these enteroviruses. For the selection of enteroviruses with oncolytic properties, several model human tumor cell lines were used. Importantly, some of the tumor cell lines were transplanted into animals and hence studies on xenografts have been carried out. The leading position in the former USSR was held by a research group of M.K. Voroshilova (Laboratory of Immunology of Enteroviruses, Institute of Poliomyelitis and Viral Encephalitis, Moscow), who has actively studied the oncolytic potential of enteroviruses [12]. This group found that live vaccines stimulate cellular immunity and can be used in cancer patients resulting in the pronounced oncolytic effects of enteroviruses. [13]. This was especially true when vaccines were administered with an interval of 2-3 weeks. Furthermore, Voroshilova and Vaganova described successful attempts of using enteroviruses in patients with gastrointestinal tract tumors [14]. Despite the initial encouraging results achieved with these viruses for the treatment of malignant neoplasms, there were also cases of uncontrolled development of viral infection in patients, which led to the emergence of a virus-specific response and, as a consequence, significantly weakened their oncolytic effect. At the same time, the lack of understanding of the mechanisms underlying the oncolytic properties of viruses complicated the introduction of OVs into clinical practice and impeded other studies on OVs for several decades. Only the recent advances in molecular biology, virology, and genetic engineering methods have made possible creating new viruses with improved selectivity for tumor cells. In recent years, research groups from the Novosibirsk State University, the Institute of Chemical Biology and Fundamental Medicine of the Siberian Branch of the Russian Academy of Sciences (Novosibirsk), the Institute of Molecular Biology named after V.A. Engelhardt RAS (Moscow), National Research University named after V.I. N.I. Pirogov (Moscow), N.N. N.N. Blokhin (Moscow), Research Institute of Experimental and Clinical Medicine 
(Novosibirsk) and a number of other scientific centers in Russia have accelerated their work on various OVs.

\section{Diversity of viruses as the basis for the development of new OVs}

The collect-and-screen approach in the field of OVs has been widely used for various virus strains and in vitro tumor cell models (see, for example, [15-18]). It should be noted that the topicality and employability of this approach is still justifiable [19]. In fact, the old idea of selecting specific anti-tumor viruses among the naturally occurring viruses is very attractive. There is incessant attention to parvoviruses [10], as the simplest DNAcontaining viruses with pronounced oncolytic activity. Various poxviruses [21], enteroviruses [22] [23], and all viral clades [24] are being actively studied in this respect as well. A different approach consists of selecting those viruses that are known to have good biosafety profiles and are easy to work with. In this respect, the vaccinia virus and as well as coxsackie virus have attracted a considerable attention $[19,25,26,28-30]$. Combining these two practical themes, several Russian groups have focused their efforts on adenoviruses as arguably the most promising candidates for virotherapy [31,32].

In fact, a strong argument in favor of using wild type OVs has been brilliantly formulated by P. Chumakov: OVs can be viewed upon as therapeutic means featuring "naturelikeness" [33]. Nevertheless, it would be too naïve to assume that certain viruses specifically have evolved in order to fight tumors. On the contrary, many viruses are oncogenic by their nature. This hypothesis was clearly articulated as early as in 1930-s by a Soviet scientist G. Zilber. The latter even managed to experimentally test his "virogenetic" theory on rodents during his imprisonment in GULAG [34]. Moreover, the infectious burden is one of the most important factors that determine the species-specific lifespan on the evolutionary scale [35].

From the practical point of view, it is important to note that virus-mediated oncolysis can be considered as a side effect defined by the features of cancer cells, e.g. accumulation of genomic aberrations that dampen the antiviral defense. Accordingly, one can speculate that tumors, due to their immunosuppressive features, can serve as backdoors for emergent infections and hence facilitate zoonotic transmission.

Undoubtedly, the efficacy of anti-tumor activity of OVs in vivo is the integral result of their interactions with both cancer cells and the immune cells of the host. During the evolution, viruses have developed various mechanisms to control the immune response, which, in principle, can be redirected to destroy cancer cells through eliciting both antiviral and anti-tumor immune responses. Importantly, the infection of individual tumor cells stimulates the so called abscopal effect, the destruction of its uninfected areas, including metastases [36]. This effect is achieved by the release of a wide range of antigens upon cell death, i. e. death associated molecular patterns (DAMPs), which in turn trigger both innate and acquired anti-tumor immune responses [37,38].

\section{Top priorities for development of OVs in Russia}

It should be noted that at present, the clinical use of OVs is considered to be the "weapon of last choice". Historically, OVs can only be prescribed against the most aggressive and incurable tumors at the late stages of their progression when there is no response to any other type of therapy. The most promising target for the development of OVs in Russia is considered to be brain tumors, glioblastoma especially. In addition, pancreatic cancer is emerging as a novel target for virotherapy. The main argument for the choice of these particular neoplasms (Fig. 1) is the lack of effective means at the present time, together with the severity of these diseases [39]. Considering the amount of research funding, it is the therapy of brain tumors that has apparently gained the highest state priority for oncoscience in Russia [40-42]. 


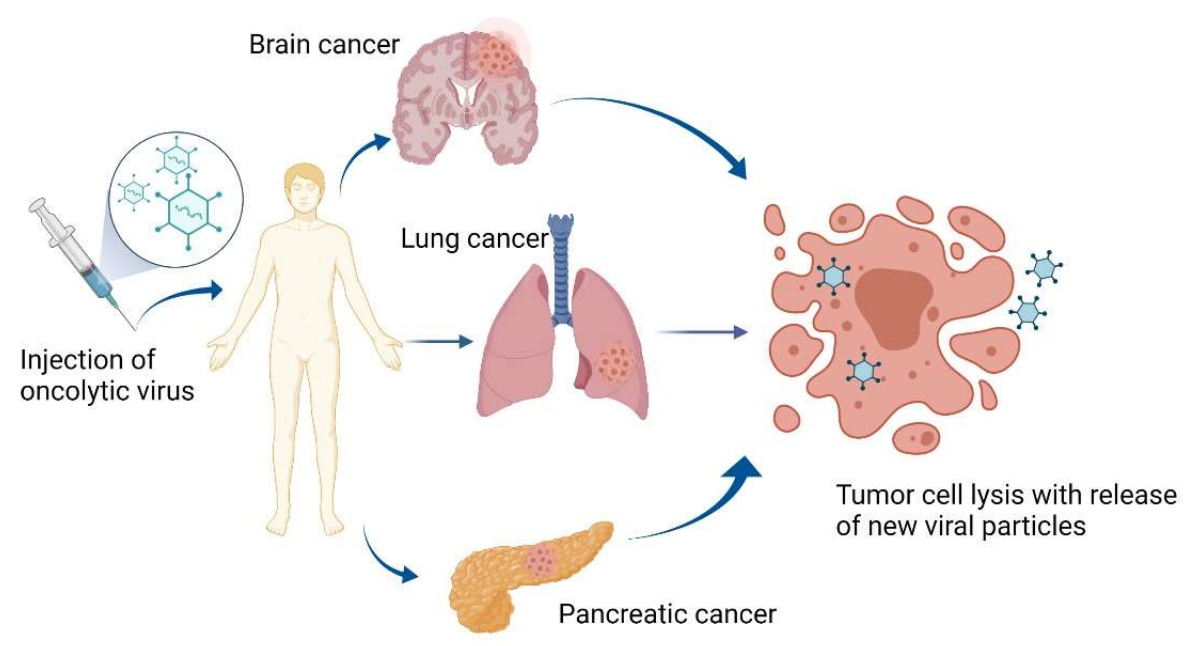

Figure 1. A general scheme depicting the ways of implementation of replicationcompetent viruses to treat various malignancies.

\section{Glioblastoma}

Tumors of the central nervous system (CNS) make up a small share among malignant neoplasms in the population, but they are characterized by low detection rates in the early stages and are extremely difficult to treat. Among adult patients, the vast majority are represented by various types of gliomas, mainly in the form of diffuse grade II-IV tumors. Of these, the most common is glioblastoma multiforme (average incidence rate 3.19/100,000 population, median age of diagnosis - 64 years, median overall survival - 318 months, and median progression free survival as low as 0.7-6 months [43,44]). Complete resection is usually impossible, since in most cases, by the time of detection, the tumor affects the parts of the brain that control muscle contractions, the organs of perception and higher nervous activity. Standard protocols of glioblastoma treatment in Russia include tumor resection followed by radiation therapy and/or chemotherapy with temozolomide $[45,46]$. In general, progress in chemotherapy for glioblastoma multiforme is rather slow; the practical list of available agents is limited to temozolomide alone or in combination with anti-angiogenic agents, such as bevacizumab that slightly prolongs progression-free survival but does not increase overall patient survival with temozolomide $[47,44]$. In pediatric brain tumors temozolomide sometimes may be successfully synergized by PARP inhibition [48]. Temozolomide is one of the few therapeutic molecules that effectively crosses the barrier and accumulates in tumor tissue. However, its genotoxic effect is neutralized by DNA repair mechanisms. Another difficulty in the treatment of brain tumors, particularly in glioblastomas, in particular, is their cellular heterogeneity [49,50]. Some of the cells form a population of so-called glioblastoma cancer stem cells, which are more resistant to radiation and chemotherapy. In addition, they can differentiate into other types of tumor cells (progenitor like tumor cells), thereby facilitating the patient's fast exit from remission [51].

Finally, glioblastoma cells have the ability to develop resistance to a wide range of chemotherapy drugs $[52,45,53]$.

\section{OVs in glioblastoma treatment}

So far, the highest efficacy in the treatment of gliomas has been shown for paramyxoviruses, particularly Newcastle avian disease virus (NDV, a single-stranded RNA virus, non-pathogenic to humans). The exact mechanism underlying the specific 
oncolytic activity of this virus remains unknown. Infection of tumor cells has been shown to activate both antiviral and anti-tumor immune responses via a Ras-mediated tyrosine kinase signaling pathway. By 2020, only one phase I / II clinical trial was conducted on the treatment of recurrent glioblastoma multiforme with the NDV-HUJ strain in 11 patients [54]. Tolerable doses have not been determined due to its minimal toxicity.

Table. Oncolytic viruses studied in Russia in recent years

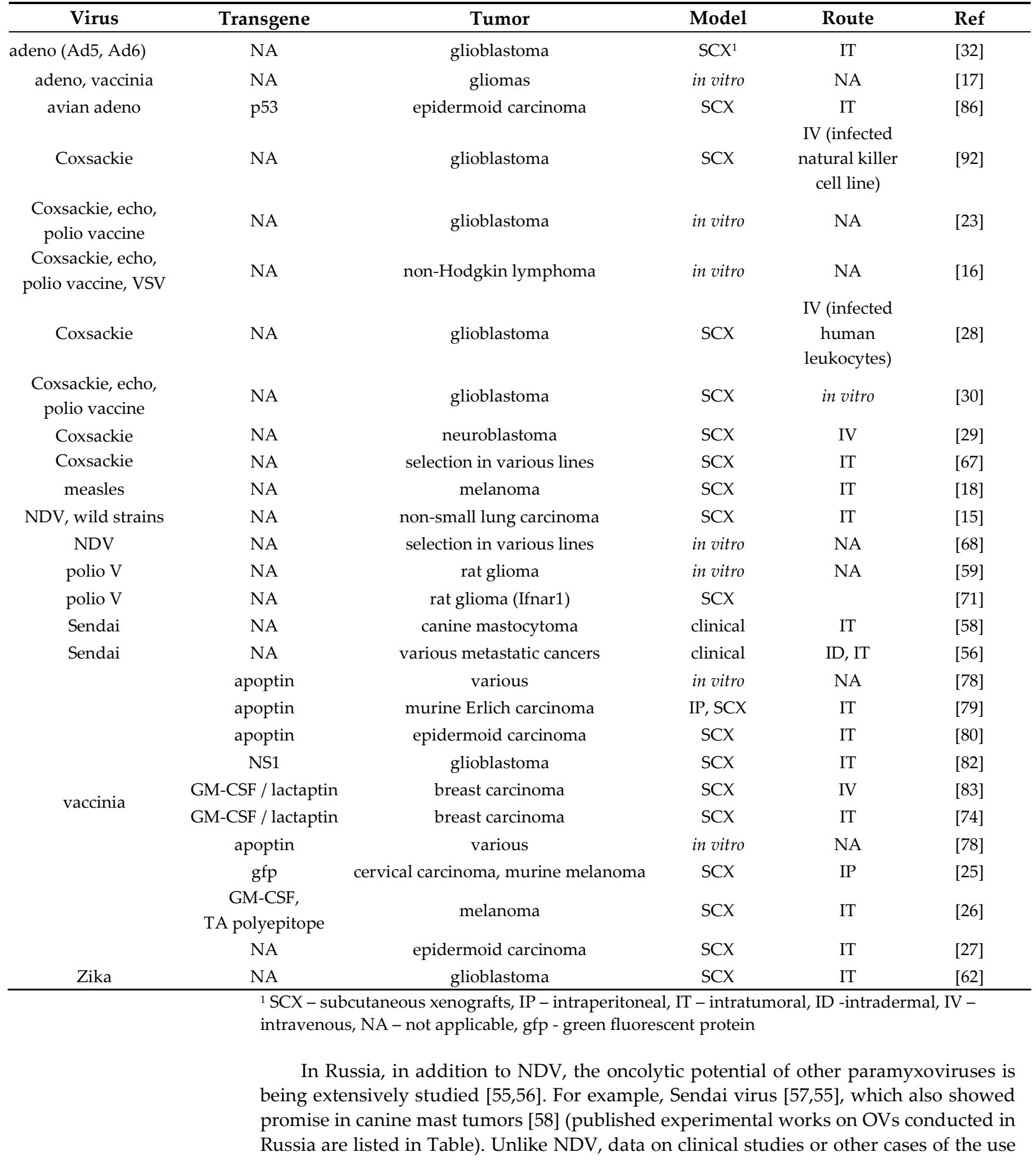


of this virus for the treatment of CNS tumors in humans have not been published in open sources. Unfortunately, most studies on polio vaccine virus in Russia have been limited to rat glioma [59,60] with the exception of [23]. The Zika virus, a representative of flaviviruses, has recently attracted particular interest, since it exhibits a significant selectivity towards glioblastoma stem cells [61,62].

\section{OVs administration routes and permeation through BBB}

The main reason for the usual failure of OVs is the fact that a number of natural barriers must be overcome during the penetrance of the oncolytic virus into the tumor. Like any nanoscale object, most viruses are nonspecifically removed from the bloodstream by the liver, lungs, and spleen. This barrier can be overcome by non-covalent modification of the surface of viruses with molecules disguising them from the immune system and thereby prolonging circulation. Polymers of both natural and synthetic origin are used for this camouflage. The first class includes dextran, polysialic acid, hyaluronic acid, chitosan, and heparin, the second - polyethylene glycol, polyacrylamide, and others. Also, preliminary administration of, for example, magnetic polysialized particles can be used, which repels the immune response to itself and ensure the prolongation of circulation. The next obstacle is the activation of acquired antiviral immunity and hence the rapid inactivation of viral particles. This is especially true in case of the use of viruses common to the population, for example, adenoviruses of serotypes 3 and 7, or in pathogenic viral families for which vaccination programs are deployed, for example, morbilliviruses. One of the strategies to overcome this limitation is the use of non-immunogenic viruses, for example, viruses of other animal species, or recombinant viruses with altered epitopes. On the other hand, sometimes pre-existent immunity boosts anti-tumor effects of OV [63]

The poor permeability of the blood-brain barrier (BBB) is the main factors for the low efficacy of chemotherapy for brain tumors [64]. BBB is composed from a complex mixture of endothelium (Fig. 2), vascular and glial cells, primarily astrocytes. These tight intercellular contacts prevent the passive transport of charged molecules weighing more than $400 \mathrm{Da}$, transport of necessary molecules is mainly carried out by receptor-mediated endocytosis in epithelial cells using transport proteins (for example, transferrin and lactoferrin). Traditionally, the use of tissue-specific viral strains was considered promising. For example, some types of rhabdoviruses and paramyxoviruses can penetrate the BBB and infect tumor cells.

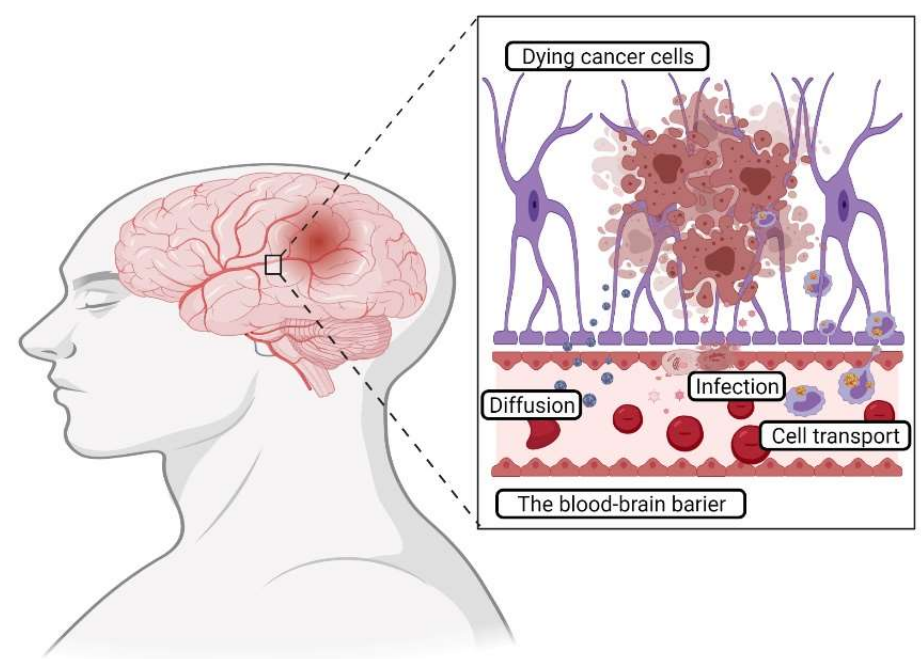

Figure 2. Importance of the blood-brain barrier in oncolytic virotherapy of brain tumors.

To date, however, most of developments in this area involve intratumoral administration. This approach seems to be the most effective for the treatment of surgically accessible 
neoplasms in the early stages. At the same time, it is not suitable for diffuse tumors, since the OV predominantly affects the injection site and spreads very little further. This is due to the high density of cell contacts in the tumor tissue and poor virus release even during cell death. Additionally, high density prevents the infiltration of immune cells into the tumor stroma. This limitation can be overcome by using recombinant viruses expressing various extracellular proteases, for example elastases, which stimulate the spread of the virus [65]. However, such a step can lead to the dissemination of cancer cells and metastasis in the absence of their full-fledged infection, stimulating the development of the disease. In theory, systemic delivery allows targeting cancer cells regardless of their location, which is important for inaccessible neoplasms, for example, the central nervous system or pancreas.

Late stages of glioma development are characterized by degradation of the blood-brain barrier (BBB), thereby promoting efficient delivery of therapeutic molecules to their targets. However, wherever its integrity is preserved, it protects not only the parenchyma, but also infiltrated malignant tumor cells from the action of drugs.

\section{Genomic engineering of OVs}

Potentially, OVs may become extremely potent therapeutic means both due to their ability to modulate the immune response and to a variety of mechanisms available to control their own activity. However, at the same time, it is still obvious that we are in the infant stage of the development OVs as conventional therapeutics [66-68]. OV development may be compromised by genetic drift during the long-term cultivation of the virus leading to uncontrollable changes in its useful oncolytic properties [69] [70]. Therefore, radical approaches employing genetic engineering are mandatory. Relatively simple changes such as knockout of unwanted genes have been practiced for a long time, for example, for several strains of poliovirus [71]. However, it is evident that without deep modifications of their genomes, the potential of viral-based oncolytics will never be fully achieved, remaining at the level of rare clinical trials with very limited number of patients. Currently, the insertion of various transgenes, for example, suicidal cassettes, fusogen proteins or growth factors, is being investigated, which will make it possible to further increase the efficacy of viruses, especially adenoviruses [72]. Further, there is no doubt that for practically successful OVs, it is important to select effective transgenes for insertion into the viral genome. The most promising candidates are transgenes that increase the likelihood of crossing the BBB, such as the ferritin heavy chain (FTH1) gene, immune recognition of malignant cells, for example, EGF gene fragments, activation of antitumor immunity, for example, GM-CSF [73-75] (Fig 3), suicidal cassettes such as the HSV-TK thymidine kinase gene, and others. 


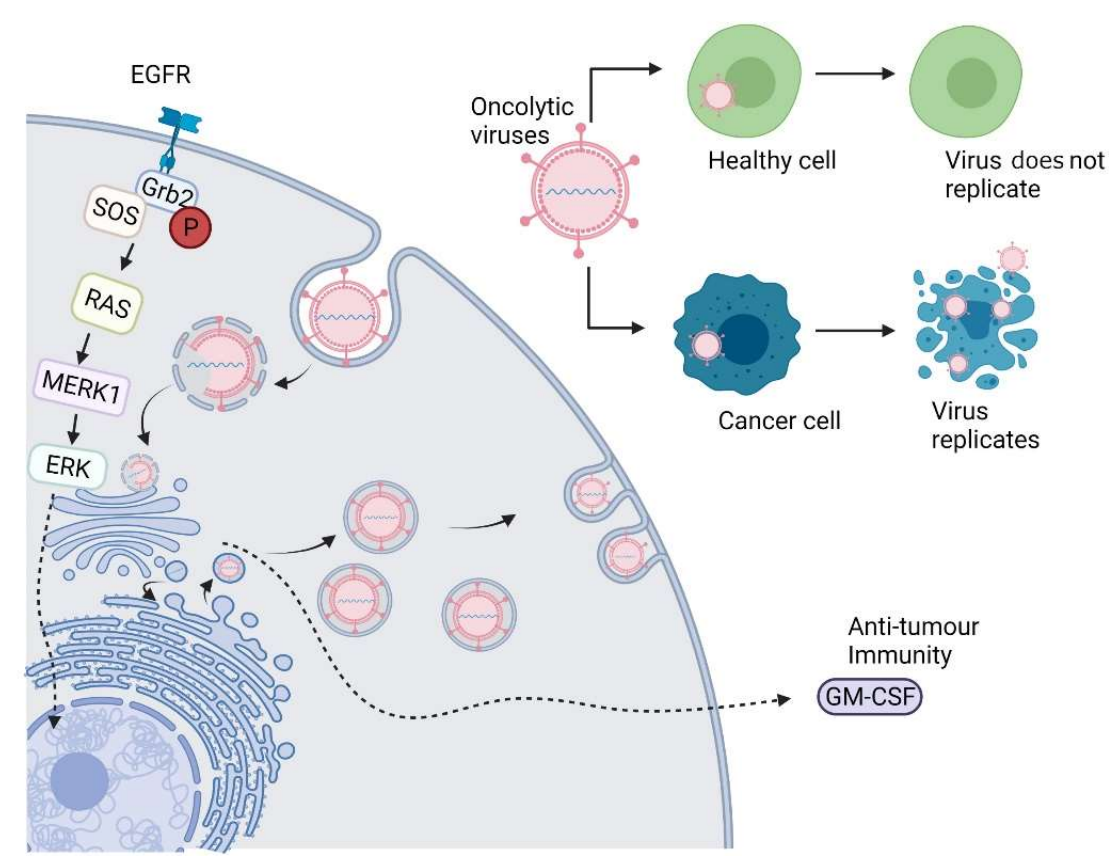

Figure 2. GM-CSF is one of the most popular transgenes for OVs.

After entering the tumor, OVs should, on the one hand, have sufficient activity for effective replication and dissemination, and on the other, avoid premature activation of intra- and extracellular mechanisms of the antiviral response. Such a fine balance can be achieved by controlling the properties of viruses via modifying their genome, including the replacement of promoter sequences with those that are active in tumors to ensure their tumor-specific expression [76] Also, the genome of the virus can be modified by including transgenes that enhance the antitumor immune response, for example, through the expression of granulocyte-macrophage colony-stimulating factor (GM-CSF), tumor necrosis factor alpha (TNF $\alpha$ ) and various interleukins (for example, IL12 [77]).

A separate problem is the effective elimination of cancer cells not only by activating or redirecting various types of immune response, but also by inducing apoptosis or virusmediated lysis. However, it should be noted that tumors have developed numerous mechanisms how to inactivate the apoptotic cues. From this perspective, the viralmediated oncolysis appears to be a more attractive scenario. The traditional approach to this is the use of specific serotypes of viruses, such as syncytium-forming viruses, primarily paramyxoviruses (for example, pseudo-plague of chickens or Newcastle disease (NDV) [56] that effectively disguise from the surveillance of the immune system. Further, an insertion of suicidal cassettes such the herpes virus thymidine kinases into the viral genome remains to be a popular choice in constructing OVs. The product of this gene, thymidine kinase from the Herpes Simplex Virus (HSV), when introduced into cells, can phosphorylate the nucleotide analogue of acyclovir and turns it into a toxic compound, causing massive cell death. In addition, among suicidal cassettes such the herpes virus thymidine kinase remain to be the most popular ones. The product of this gene, when introduced into cells of the nucleotide analogue of acyclovir, phosphorylates it and turns it into a toxic compound, causing apoptosis.

Overall, quite a number of different transgenes have been explored to boost the action of OVs in Russia. For example, the apoptin gene from chicken anemia virus have been reported to improve oncolytic action of vaccinia virus [78-80]. A similar approach has been tested for adenoviruses [81]. Toxic protein NS1 have been also evaluated for this purpose $[82,83]$. In principle, any variants of genomic modifications attract attention, especially for 
well-studied models such as adenoviruses [84,85]. Restoration of normal p53 with the use of adenoviral vectors also has been explored [86].

\section{Reducing side effects of virotherapy}

A wealth of experimental data strongly argues for the relatively low toxicity of herpes viruses, adenoviruses, poxviruses, and paramyxoviruses. At present, various clinical studies have shown the safety of both intratumoral and systemic administration of OVs, even when using high concentrations of the virus (up to $2 \times 10^{13}$ particles) [87]. The key factors in the development of a therapy based on OVs are the specific type of virus and the intended route of administration

The thymidine kinase-acyclovir system additionally provides control over the spread of the virus. Accordingly, in the event of complications, infected cells can be eliminated with standard antiherpetic drugs such as acyclovir.

As an example of such effects, one can mention that oncolytic HSV may cause activation of dormant herpesvirus infection, hypotension, tachycardia, pleural effusion, cerebral edema with speech disorders and seizures. In addition, oncolytic adenovirus may cause pleural effusion with dehydration, hypokalemia, liver malfunction. All of the aforementioned treatments for viruses posed a threat to the health of patients who participated in these clinical trials. Pleural effusion can lead to shortness of breath and even asphyxiation. Fortunately, most of these severe adverse events have been resolved after discontinuation of treatment or symptomatic treatment, rarely threatening patients' lives [88].

\section{Epidemiologic safety of OVs}

Safety considerations of the practical use of any viruses play ever-increasing role in the decision of implementing a specific type of OVs. The valid concerns that a virus may spread from a laboratory to the production facility or patients themselves may give rise to new aggressive and deadly infections. The creation of viruses, modified in such a way that they become replication-deficient, should eliminate this kind of fear. But even more promising is the assembly of clinical OVs and gene-therapeutic virus-like particles from individual components completely in vitro, avoiding any living cells, at the final stages of viral assembly. Such strategies aim to develop viral particles with the highest degree of safety inherent in their design and, accordingly, cut off from hypothetical threats of the spread of viruses from laboratories, factories and clinics into the environment and further into the population.

\section{Practical use of OVs in Russia}

Much attention is being paid to combining OVs with other means, for example, the there is hope that OVs may decrease stiffness of the tumor extracellular matrix and increase CAR-T access [89,90] or that dendritic cells may be used as carriers of OV [91] as well as natural killer cell lines [92].

In the 90 s a Sendai virus has been tested against various inoperable tumors. Some patients showed a long-term remission with resorption of primary tumors and metastases [56]. However, this virotherapy was not effective for the majority of patients.

The first registered OV in Russia is Cancerolysin, a mutant variant of human Ad5, defective in the E1B 55K protein gene, prepared at Scientific Center "Vector". Preliminary results indicated that in patients with disseminated head and neck cancer it was well tolerated [93]. 


\section{Conclusions and Future directions}

Oncolytic viruses are now being tested all over the world, including Russia, and are considered as perspective agents against the most aggressive tumors resistant to traditional therapies. The old approach of adapting replication competent unmodified viruses, for example, VSV [97], and repurposing vaccine strains such as the yellow fever one still looks promising in the fight against pancreatic cancer and others [98]. However, given the heterogeneity of the brain tissues and the BBB penetrance problem that includes low immunity inside the brain, novel glioblastoma-specific OVs should be designed through deep modifications of the existing OVs by enhancing their oncotropism, ability to penetrate the $\mathrm{BBB}$, and improved pharmacokinetics (including resistance to the immune system). It is believed that only replication-deficient OVs should be used in cancer therapy in the future. It is advisable to employ the conception of transient (i.e., existing only immediately after the modification of viruses) tropism, which undoubtedly should guarantee the increased epidemiological safety of oncolytic viruses. This approach is especially promising if certain proteins are conjugated with the virus surface that cannot be successfully produced in the cells in which the virus is assembled. For such a conjugation system, it is tempting to use a transglutaminase, an enzyme that cross-links glutamic acid residues with amine groups of other amino acids [94]. The recent work [95] indicates that this approach is more efficient in obtaining the artificial viruses with altered specificity when compared with similar chemical approaches [96]. This opens innumerable possibilities for virion functionalization by conjugation, for example, with ferromagnetic nanoparticles followed by combination therapies. Importantly, this approach is currently being actively pursued in the Institute of Poliomyelitis named after Chumakov. Considering various trade-offs, the most promising approach for the future OVs application are surface-modified adeno-associated viruses, armed with transgenic enzymes that convert prodrugs into their active forms in situ. This approach attracted relatively little attention in Russia in the past but is now set to rocket-launch at several research institutes. In conclusion, we believe that despite limited success achieved by OVs to date due to specific problems of OVs described above, this multidisciplinary approach has enormous potential. Importantly, given the rich history of research in virology, Russian virologists and molecular biologists strive to succeed in this field.

Author Contributions: Conceptualization, N.A.B. and A.A.I.; writing-original draft preparation, N.M.K., N.B.P., J.M.S.-P., N.A.B.; writing-review and editing, N.M.K., N.B.P., N.A.B.; visualization, J.M.S.-P.; supervision, N.A.B., A.A.I.; project administration, M.M.K, N.A.B., A.A.I.; funding acquisition, N.A.B., A.A.I. All authors have read and agreed to the published version of the manuscript.

Institutional Review Board Statement: Not applicable.

Informed Consent Statement: Not applicable.

Data Availability Statement: Not applicable.

Acknowledgments: The authors are greatful to Y.M. Rosenberg for crticial reading of the manuscript.

Conflicts of Interest: The authors declare no conflict of interest.

\section{References}

1. Alberts, P.; Tilgase, A.; Rasa, A.; Bandere, K.; Venskus, D. The Advent of Oncolytic Virotherapy in Oncology: The Rigvir ${ }^{\circledR}$ Story. European Journal of Pharmacology 2018, 837, 117-126, doi:10.1016/j.ejphar.2018.08.042.

2. Liang, M. Oncorine, the World First Oncolytic Virus Medicine and Its Update in China. Curr Cancer Drug Targets 2018, 18, 171176, doi:10.2174/1568009618666171129221503.

3. Haitz, K.; Khosravi, H.; Lin, J.Y.; Menge, T.; Nambudiri, V.E. Review of Talimogene Laherparepvec: A First-in-Class Oncolytic Viral Treatment of Advanced Melanoma. J Am Acad Dermatol 2020, 83, 189-196, doi:10.1016/j.jaad.2020.01.039. 
4. Kelly, E.; Russell, S.J. History of Oncolytic Viruses: Genesis to Genetic Engineering. Molecular Therapy 2007, 15, 651-659, doi:10.1038/sj.mt.6300108.

5. Dock, G. The Influence Of Complicating Diseases Upon Leukæmia. Am. J. Med. Sci. 1904, 127, 563-592.

6. de Pace, N.G. Sulla Scomparsa Di Un Enorme Cancro Vegetante Del Collo Dell Utero Senza Cura Chirurgica. Ginecologia 1912, 9, 82-88. Ital.

7. Shen, R.M. Problems Of Medical Virology. Medgiz: Moscow, USSR, 1949; p. 347. Russ.

8. Moore, A.E. The Destructive Effect of the Virus of Russian Far East Encephalitis on the Transplantable Mouse Sarcoma 180. Cancer 1949, 2, 525-534, doi:10.1002/1097-0142(194905)2:3<525::aid-cncr2820020317>3.0.co;2-o.

9. Levkovich, E.N.; Karpovich, L.G. A Comparative Study On Viruses Of The Tick-borne Encephalytis Group In Cultures of HeLa Cells. Voprosy Virusologii 1959, 30-39. Russ.

10. Sergeeva, G.I.; Levkovich, E.N. Studies On Reproduction Properties Of Certain Viruses From The Tick-borne Encephalytis Complex With Different Degrees of Neurovirulence In Tumor Cells In Vitro And In Vivo. Voprosy Virusologii 1966.

11. Levkovich, E.N.; Sergeeva, G.I. Inhibitory Action of Viruses From The Tick-borne Encephalytis Complex With Different Degrees of Neurovirulence On Murine Tumors In Vivo. Voprosy Virusologii 1966, 88-91. Russ.

12. Tsypkin, L.B.; Voroshilova, M.K.; Goryunova, A.G.; Lavrova, I.K.; Koroleva, G.A. The Morphology of Tumors of the Human Gastrointestinal Tract in Short-Term Organ Culture and the Reaction of These Tumors to Infection with Poliovirus. Cancer 1976, 38, 1796-1806, doi:10.1002/1097-0142(197610)38:4<1796::AID-CNCR2820380457>3.0.CO;2-Y.

13. Voroshilova, M.K.; Goryuniva, A.G.; Gorbachkov, E.A., Chumakov, P.M.; Oganian, T.G.; Kodkind, G.H. Studies on Cellular Immunity of Oncology Patients In The Process of Asymptomic Enteroviral Infection. Zinātne: Riga, 1977; pp. 17-20. Russ.

14. Voroshilova, M.K.; Vaganova, N.T. Treatment Of Patients With Gastro-Intestinal Tract Tumors With Live Enteroviral Vaccines. Zinātne: Riga, USSR, 1969. Russ.

15. Yurchenko, K.S.; Kovner, A.V.; Shestopalov, A.M.; Zhou, P.; Shestopalova, L.V.; Zavjalov, E.L. Oncolytic Effect of Wild-Type Newcastle Disease Virus Isolates in Cancer Cell Lines in Vitro and in Vivo on Xenograft Model. Plos One 2018, 13, doi:10.1371/journal.pone.0195425.

16. Babaeva, F. E.; Lipatova, A.V.; Kochetkov, D.V. et al. The study of oncolytic viruses reproduction in organ cultures of human lymphoid tumors. Oncohematology 2019, 14, 84-89, doi:10.17650/1818-8346-2019-14-4-84-89. Russ.

17. Razumov, I.A.; Svyatchenko, V.A.; Protopopova, E.V.; Kochneva, G.V.; Kiselev, N.N.; Gubanova, N.V.; Shilov, A.G.; Mordvinov, V.A.; Netesov, S.V.; Chumakov, P.M.; et al. Oncolytic Properties Of Some Orthopoxviruses, Adenoviruses And Parvoviruses In Human Glioma Cells. Annals RAMS 2013, 68, 4-8, doi:10.15690/vramn.v68i12.853. Russ.

18. Ammour, Y.; Ryabaya, O.; Shchetinina, Y.; Prokofeva, E.; Gavrilova, M.; Khochenkov, D.; Vorobyev, D.; Faizuloev, E.; Shohin, I.; Zverev, V.V.; et al. The Susceptibility of Human Melanoma Cells to Infection with the Leningrad-16 Vaccine Strain of Measles Virus. Viruses 2020, 12, doi:10.3390/v12020173.

19. Mach, N.; Gao, J.; Schaffarczyk, L.; Janz, S.; Ehrke-Schulz, E.; Dittmar, T.; Ehrhardt, A.; Zhang, W. Spectrum-Wide Exploration of Human Adenoviruses for Breast Cancer Therapy. Cancers (Basel) 2020, 12, doi:10.3390/cancers12061403.

20. Loktev, V.B.; Ivan'kina; T.Y.; Netesov, S.V.; Chumakov, P.M. Oncolytic Parvoviruses. New Approaches For Cancer Therapy. Vestnik Russ Acad Med Sci 2012, 67, 42-47, doi:10.15690/vramn.v67i2.121. Russ.

21. Kochneva, G.V.; Sivolobova, G.F.; Yudina, K.V.; Chumakov, P.M.; Netesov, S.V.; Babkin, I.V. Oncolytic Poxviruses. Molec Genet Microbiol Virol 2012, 27, 7-15. Russ.

22. Chumakov, P.M.; Morozova, V.V.; Babkin, I.V.; Baikov, I.K.; Netesov, S.V.; Tikunova, N.V. Oncolytic Enteroviruses. Molec Biol 2012, 46, 639-650. Russ.

23. Soboleva, A.V.; Seryak, D.A.; Gabdrakhmanova, A.F.; Sosnovtseva, A.O.; Tkhe, L.H.; Kochetkov, D.V.; Ilyinskaya, G.V.; Lipatova, A.V.; Chumakov, P.M.; Golbin, D.A. Glioblastoma Multiforme Stem Cells Are Highly Sensitive to Some Human NonPathogenic Enteroviruses. Journal of Pharmaceutical Sciences and Research 2018, 10.

24. Morozov, D.A.; Kolyadina, I.V.; Poddubnaya, I.V.; Chumakov, P.M.; Ilinskaya, G.V.; Bokhian, V.Y.; Sopova, M.I. The Potential Use Of Oncolytic Viruses In Breast Cancer: Historical Aspects And Future Prospects. J Modern Oncol 2019, 21, 31-35, doi:10.26442/18151434.2019.1.190299. Russ.

25. Goncharova, E.P.; Ruzhenkova, J.S.; Petrov, I.S.; Shchelkunov, S.N.; Zenkova, M.A. Oncolytic Virus Efficiency Inhibited Growth of Tumour Cells with Multiple Drug Resistant Phenotype in Vivo and in Vitro. J Transl Med 2016, 14, 241, doi:10.1186/s12967016-1002-x.

26. Bauer, T.V.; Tregubchak, T.V.; Maksyutov, A.Z.; Taranov; O.S.; Maksyutov; R.A.; Gavrilova, E.V.; Solovieva, O.I.; Razumov, I.A.; Zavjalov, E.L. Recombinant Vaccinia Virus Promising For Melanoma Treatment. Molec Genet Microbiol Virol 2020, 35, 97104. doi:10.17116/molgen20203802190. Russ.

27. Zonov, E.; Yunusova, A.; Richter, V.; Ryabchikova, E.; Kochneva, G.; Grazhdantseva, A. Features of the Antitumor Effect of Vaccinia Virus Lister Strain. Viruses 2016, 8, doi:10.3390/v8010020.

28. Sidorenko, A.S.; Zheltukhin, A.O.; Le, T.H.; Soboleva, A.V.; Lipatova, A.V.; Golbin, D.A.; Chumakov, P.M. Persistence Of Oncolytic Coxsackie Virus A7 In Subcutaneous Human Glioblastoma Xenografts In Mice In The Context Of Experimental Therapy. Bull Russ State Medl Univ 2018, 41-46, doi:10.24075/vrgmu.2018.032. Russ.

29. Sosnovtceva, A.O.; Karshieva, S.S.; Smirnova, G.B.; Borisova, Y.A.; Lebedinskaya, O.V.; Shubina, I.Z.; Treshalina, H.M.; Chumakov, P.M.; Chekhonin, V.P. Sensitivity Of The Transplanted Human Neuroblastoma To Oncolytic Coxsackie A7 Virus. Russ Oncol J 2017, 22, 158-163, doi:10.18821/1028-9984-2017-22-2-158-163. Russ. 
30. Zheltukhin, A.O.; Soboleva, A.V.; Sosnovtseva, A.O.; Le, T.H.; Ilyinskaya, G.V.; Kochetkov, D.V.; Lipatova, A.V.; Chumakov, P.M. Human Enteroviruses Exhibit Selective Oncolytic Activity In The Model Of Human Glioblastoma Multiforme Xenografts In Immunodeficient Mice. Bull Russ State Med Univ 2018. 42-48, doi:10.24075/vrgmu.2018.026. Russ.

31. Svyatchenko, V.A.; Tarasova M.V.; Netesov, S. V.; Chumakov P.M. Oncolytic Adenoviruses In Anti-Cancer Therapy: Current Status And Perspectives. Molec Biol 2012, 46, 556-569. Russ.

32. Romanenko, M.V.; Osipov, I.D.; Ritter, G.S.; Sizova, M.S.; Efremov, Y.R.; Netesov, S.V.; Dolgova, E.V.; Proskurina, A.S.; Bayborodin, S.I.; Potter, E.A.; et al. Oncolytic Effect of Adenoviruses Serotypes 5 and 6 against U87 Glioblastoma Cancer Stem Cells. Anticancer Research 2019, 39, doi:10.21873/anticanres.13815.

33. Chumakov, P.M. Could Oncolytic Viruses Provide A Breakthrough In Oncology? Vestnik Russ Acad Sci 2019, 89, 475-484, doi:10.31857/S0869-5873895475-484. Russ.

34. Zilber, L.A. Viral Theory of The Origin of Malignant Tumors. Medgiz: Moscow, USSR, 1946. Russ.

35. Lidsky, P.V.; Andino, R. Epidemics as an Adaptive Driving Force Determining Lifespan Setpoints. Proc Natl Acad Sci U S A 2020, 117, 17937-17948, doi:10.1073/pnas.1920988117.

36. Chouljenko, D.V.; Ding, J.; Lee, I.-F.; Murad, Y.M.; Bu, X.; Liu, G.; Delwar, Z.; Sun, Y.; Yu, S.; Samudio, I.; et al. Induction of Durable Antitumor Response by a Novel Oncolytic Herpesvirus Expressing Multiple Immunomodulatory Transgenes. Biomedicines 2020, 8, doi:10.3390/biomedicines8110484.

37. Brown, M.C.; Mosaheb, M.M.; Mohme, M.; McKay, Z.P.; Holl, E.K.; Kastan, J.P.; Yang, Y.; Beasley, G.M.; Hwang, E.S.; Ashley, D.M.; et al. Viral Infection of Cells within the Tumor Microenvironment Mediates Antitumor Immunotherapy via Selective TBK1-IRF3 Signaling. Nat Commun 2021, 12, 1858, doi:10.1038/s41467-021-22088-1.

38. Jiang, H.; Fueyo, J. Healing after Death: Antitumor Immunity Induced by Oncolytic Adenoviral Therapy. Oncoimmunology 2014, 3, e947872, doi:10.4161/21624011.2014.947872.

39. Tassone, E.; Muscolini, M.; van Montfoort, N.; Hiscott, J. Oncolytic Virotherapy for Pancreatic Ductal Adenocarcinoma: A Glimmer of Hope after Years of Disappointment? Cytokine E Growth Factor Reviews 2020, doi:10.1016/j.cytogfr.2020.07.015.

40. Stepanenko, A.A.; Chekhonin, V.P. Recent Advances in Oncolytic Virotherapy and Immunotherapy for Glioblastoma: A Glimmer of Hope in the Search for an Effective Therapy? Cancers (Basel) 2018, 10, doi:10.3390/cancers10120492.

41. Sosnovtceva, A.O.; Grinenko, N.F.; Lipatova, A.V.; Chumakov, P.M.; Chekhonin, V.P. Oncolytic Viruses For Therapy Of Malignant Glioma. Biomeditsinskaya khimiya 2016, 62, 376-390, doi:10.18097/PBMC20166204376. Russ.

42. Baklaushev, V.P.; Goryainov, S.A.; Potapov, A.A.; Pavlova, G.V.; Chehonin, V.P. Oncolytic Viruses In High-Grade Gliomas Treatment. J Clin Pract 2015, 2, 6-59. Russ.

43. Thakkar, J.P.; Dolecek, T.A.; Horbinski, C.; Ostrom, Q.T.; Lightner, D.D.; Barnholtz-Sloan, J.S.; Villano, J.L. Epidemiologic and Molecular Prognostic Review of Glioblastoma. Cancer Epidemiol Biomarkers Prev 2014, 23, 1985-1996, doi:10.1158/1055-9965.EPI14-0275.

44. Schritz, A.; Aouali, N.; Fischer, A.; Dessenne, C.; Adams, R.; Berchem, G.; Huiart, L.; Schmitz, S. Systematic Review and Network Meta-Analysis of the Efficacy of Existing Treatments for Patients with Recurrent Glioblastoma. Neurooncol Adv 2021, 3, vdab052, doi:10.1093/noajnl/vdab052.

45. Stepanenko, A.A.; Chekhonin, V.P. On the Critical Issues in Temozolomide Research in Glioblastoma: Clinically Relevant Concentrations and MGMT-Independent Resistance. Biomedicines 2019, 7, E92, doi:10.3390/biomedicines7040092.

46. Absalyamova, O.V.; Kobyakov, G.L.; Ryzhova, M.V.; Poddubskiy, A.A.; Inozemtseva, M.V.; Lodygina, K.S. Outcomes of Application of Modern First-Line Chemotherapy Regimens in Complex Treatment of Glioblastoma Patients. Zh Vopr Neirokhir Im N N Burdenko 2016, 80, 5-14, doi:10.17116/neiro20168065-14. Russ.

47. Chinot, O.L.; Wick, W.; Mason, W.; Henriksson, R.; Saran, F.; Nishikawa, R.; Carpentier, A.F.; Hoang-Xuan, K.; Kavan, P.; Cernea, D.; et al. Bevacizumab plus Radiotherapy-Temozolomide for Newly Diagnosed Glioblastoma. N Engl J Med 2014, 370, 709-722, doi:10.1056/NEJMoa1308345.

48. Valiakhmetova, A.; Gorelyshev, S.; Konovalov, A.; Trunin, Y.; Savateev, A.; Kram, D.E.; Severson, E.; Hemmerich, A.; Edgerly, C.; Duncan, D.; et al. Treatment of Pediatric Glioblastoma with Combination Olaparib and Temozolomide Demonstrates 2-Year Durable Response. Oncologist 2020, 25, e198-e202, doi:10.1634/theoncologist.2019-0603.

49. Korshunov, A.; Chavez, L.; Sharma, T.; Ryzhova, M.; Schrimpf, D.; Stichel, D.; Capper, D.; Sturm, D.; Kool, M.; Habel, A.; et al. Epithelioid Glioblastomas Stratify into Established Diagnostic Subsets upon Integrated Molecular Analysis. Brain Pathol 2018, 28, 656-662, doi:10.1111/bpa.12566.

50. Kim, E.L.; Sorokin, M.; Kantelhardt, S.R.; Kalasauskas, D.; Sprang, B.; Fauss, J.; Ringel, F.; Garazha, A.; Albert, E.; Gaifullin, N.; et al. Intratumoral Heterogeneity and Longitudinal Changes in Gene Expression Predict Differential Drug Sensitivity in Newly Diagnosed and Recurrent Glioblastoma. Cancers (Basel) 2020, 12, E520, doi:10.3390/cancers12020520.

51. Dey, M.; Ulasov, I.V.; Lesniak, M.S. Virotherapy against Malignant Glioma Stem Cells. Cancer Lett 2010, 289, 1-10, doi:10.1016/j.canlet.2009.04.045.

52. Stavrovskaya, A.A.; Shushanov, S.S.; Rybalkina, E.Y. Problems of Glioblastoma Multiforme Drug Resistance. Biochemistry (Mosc) 2016, 81, 91-100, doi:10.1134/S0006297916020036.

53. Azam, Z.; TO, S.T.; Tannous, B.A. Mesenchymal Transformation: The Rosetta Stone of Glioblastoma Pathogenesis and Therapy Resistance. Adv Sci (Weinh) 2020, 7, doi:10.1002/advs.202002015. 
54. Freeman, A.I.; Zakay-Rones, Z.; Gomori, J.M.; Linetsky, E.; Rasooly, L.; Greenbaum, E.; Rozenman-Yair, S.; Panet, A.; Libson, E.; Irving, C.S.; et al. Phase I/II Trial of Intravenous NDV-HUJ Oncolytic Virus in Recurrent Glioblastoma Multiforme. Mol Ther 2006, 13, 221-228, doi:10.1016/j.ymthe.2005.08.016.

55. Matveeva, O.V.; Kochneva, G.V.; Zainutdinov, S.S.; Ilyinskaya, G.V.; Chumakov, P.M. Oncolytic Paramyxoviruses: Mechanism Of Action, Preclinical And Clinical Studies. Molec Biol 2018, 52, 306-322, doi:10.7868/S0026898418030023. Russ.

56. Matveeva, O.V.; Chumakov, P.M.; Guo, Z.S.; Shabalina, S.A. Oncolysis by Paramyxoviruses: Multiple Mechanisms Contribute to Therapeutic Efficiency. Molecular Therapy - Oncolytics 2015, 2, doi:10.1038/mto.2015.11.

57. Matveeva, O.V.; Kochneva, G.V.; Netesov, S.V.; Onikienko, S.B.; Chumakov, P.M. Mechanisms of Oncolysis by Paramyxovirus Sendai. Acta Naturae 2015, 7, 6-16.

58. Ilyinskaya, G.V.; Mukhina, E.V.; Soboleva, A.V.; Matveeva, O.V.; Chumakov, P.M. Oncolytic Sendai Virus Therapy of Canine Mast Cell Tumors (A Pilot Study). Front Vet Sci 2018, 5, 116, doi:10.3389/fvets.2018.00116.

59. Sosnovtseva, A.O.; Lipatova, A.V.; Grinenko, N.F.; Baklaushev, V.P.; Chumakov, P.M.; Chekhonin, V.P. Sensitivity of C6 Glioma Cells Carrying the Human Poliovirus Receptor to Oncolytic Polioviruses. Bull Exp Biol Med 2016, 161, 821-825, doi:10.1007/s10517-016-3520-1. Russ.

60. Sosnovtseva, A.O.; Zheltukhin, A.O.; Lipatova, A.V.; Chumakov, P.M.; Chekhonin, V.P. Oncolytic Activity of the Vaccine Strain of Type 3 Poliovirus on the Model of Rat Glioma C6 Cells. Bull Exp Biol Med 2019, 167, 111-115, doi:10.1007/s10517-019-044726. Russ.

61. Zhu, Z.; Gorman, M.J.; McKenzie, L.D.; Chai, J.N.; Hubert, C.G.; Prager, B.C.; Fernandez, E.; Richner, J.M.; Zhang, R.; Shan, C.; et al. Zika Virus Has Oncolytic Activity against Glioblastoma Stem Cells. J Exp Med 2017, 214, 2843-2857, doi:10.1084/jem.20171093.

62. Svyatchenko, V.A.; Razumov, I.A.; Protopopova, E.V.; Demina, A.V.; Solovieva, O.I.; Zavjalov, E.L.; Loktev, V.B. Zika virus has an oncolytic activity against human glioblastoma U87 cells. Vavilov J Genet Breeding 2018, 22, 1040-1045, doi:10.18699/VJ18.448 Russ.

63. Zamarin, D.; Wolchok, J.D. Potentiation of Immunomodulatory Antibody Therapy with Oncolytic Viruses for Treatment of Cancer. Mol Ther Oncolytics 2014, 1, 14004, doi:10.1038/mto.2014.4.

64. Ganipineni, L.P.; Danhier, F.; Préat, V. Drug Delivery Challenges and Future of Chemotherapeutic Nanomedicine for Glioblastoma Treatment. J Control Release 2018, 281, 42-57, doi:10.1016/j.jconrel.2018.05.008.

65. Kuznetsova, I.; Arnold, T.; Aschacher, T.; Schwager, C.; Hegedus, B.; Garay, T.; Stukova, M.; Pisareva, M.; Pleschka, S.; Bergmann, M.; et al. Targeting an Oncolytic Influenza A Virus to Tumor Tissue by Elastase. Mol Ther Oncolytics 2017, 7, 37-44, doi:10.1016/j.omto.2017.09.002.

66. Zainutdinov, S.S.; Kochneva, G.V.; Netesov, S.V.; Chumakov P.M.; Matveeva, O.V. Directed Evolution as a Tool for the Selection of Oncolytic RNA Viruses with Desired Phenotypes. Oncolytic Virotherapy 2019, 8, doi:10.2147/OV.S176523.

67. Svyatchenko, V.A.; Ternovoy, V.A.; Kiselev, N.N.; Demina, A.V.; Loktev, V.B.; Netesov, S.V.; Chumakov, P.M. Bioselection of Coxsackievirus B6 Strain Variants with Altered Tropism to Human Cancer Cell Lines. Archives of Virology 2017, 162, doi:10.1007/s00705-017-3492-0.

68. Yurchenko, K.S.; Jing, Y.; Shestopalov, A.M. Adaptation of the Newcastle Disease Virus to Cell Cultures for Enhancing Its Oncolytic Properties. Acta Naturae 2019, 11, 66-73.

69. Zainutdinov, S.S.; Sivolobova, G.F.; Grazhdantseva, A.A.; Kochneva, G.V. Changes In Oncolytic Activity of Sendai Virus During Adaptation To Cell Cultures. Molecular Genetics, Microbiology and Virology 2019, 498-500. Russ.

70. Soboleva, A.V.; Lipatova, A.V.; Kochetkov, D.V.; Chumakov, P.M. Changes In The Sensitivity Of Human Glioblastoma Cells To Oncolytic Enteroviruses Induced By Passaging. Bull Russ State Med Univ 2018, 37-41, doi:10.24075/vrgmu.2018.025. Russ.

71. Sosnovtseva A.O., Chekhonin V.P., Zheltukhin A.O., Lipatova A.V., Chumakov P.M. Oncolytic Activity Of The Vaccine Strain Of Type 3 Poliovirus On The Model Of Rat Glioma C6 Cells. Bull Exp Biol Med 2019, 167, 111-115. Russ.

72. Ulasov, I.V.; Borovjagin, A.V.; Schroeder, B.A.; Baryshnikov, A.Y. Oncolytic Adenoviruses: A Thorny Path to Glioma Cure. Genes Dis 2014, 1, 214-226, doi:10.1016/j.gendis.2014.09.009.

73. Grazhdantseva, A.A.; Sivolobova, G.F.; Tkacheva, A.V.; Gileva, I.P.; Kochneva, G.V.; Kuligina, E.V.; Rikhter, V.A. Highly Effective Production Of Biologically Active, Secreted, Human Granulocyte-Macrophage Colony-Stimulating Factor By Recombinant Vaccinia Virus. Appl Biochem Microbiol 2016, 52, 685-691. Russ.

74. Kochneva, G.V.; Tkacheva, A.V.; Sivolobova, G.F.; Grazhdantseva, A.A.; Yunusova, A.Yu.; Ryabchikova, E.I.; Kuligina, E.V.; Koval, O.A.; Rikhter, V.A. Antitumor Potential Of Recombinant Vaccinia Virus Strain, Which Produces A Secreted Chimera Protein, Composed Of Human Gm-Csf And Oncotoxic Peptide Lactaptin. Russian J Biopharmaceut 2017, 9, 11-21. Russ.

75. Koval, O.; Galina Kochneva, G.; Tkachenko, A.; Troitskaya, O.; Sivolobova, G.; Grazhdantseva, A.; Nushtaeva, A.; Kuligina, E.; Richter, V. Recombinant Vaccinia Viruses Coding Transgenes of Apoptosis-Inducing Proteins Enhance Apoptosis But Not Immunogenicity of Infected Tumor Cells. Biomed Res Int 2017; 3620510. doi:10.1155/2017/3620510. 1

76. Liu, B.; Paton, J.F.; Kasparov, S. Viral Vectors Based on Bidirectional Cell-Specific Mammalian Promoters and Transcriptional Amplification Strategy for Use in Vitro and in Vivo. BMC Biotechnol 2008, 8, 49, doi:10.1186/1472-6750-8-49.

77. Patel, S.; Bui, T.T.T.; Drake, A.F.; Fraternali, F.; Nikolova, P.V. The P73 DNA Binding Domain Displays Enhanced Stability Relative to Its Homologue, the Tumor Suppressor P53, and Exhibits Cooperative DNA Binding. Biochemistry 2008, 47, 32353244, doi:10.1021/bi7023207. 
78. Kochneva, G.V.; Grazhdantseva, A.A.; Yudin, P.V.; Sivolobova, G.F.; Popov, E.G.; Netesov, S.V.; Chumakov, P.M.; Babkina, I.N.; Lupan, T.A.; Shvalov, A.N.; Babkin, I.V. Apoptin Enhances The Oncolytic Activity Of Vaccinia Virus In Vitro. Molec. Biol. 2013, 47, 733-742 doi:10.7868/S0026898413050078. Russ.

79. Zonov, E.V.; Tupitsyna, A.V.; Ryabchikova, E.I.; Kochneva, G.V. The In Vivo Antitumor Effect Of The Apoptin-Producing Recombinant Vaccinia Virus Strain Is Associated With Blockage Of Mitotic Division Of Cancer Cells. Molecular Genetics, Microbiology and Virology. 2016, 31, 233-239, doi:10.18821/0208-0613-2016-34-4-154-159. Russ.

80. Kochneva, G.; Yunusova, A.; Popov, E.; Netesov, S.; Chumakov, P.; Ryabchikova, E.; Grazhdantseva, A.; Sivolobova, G.; Taranov, O.; Zonov, E. Apoptin Enhances the Oncolytic Properties of Vaccinia Virus and Modifies Mechanisms of Tumor Regression. Oncotarget 2014, 5, doi:10.18632/oncotarget.2579.

81. Ternovoy, V.A.; Svyatchenko V.A.; Tarasova, M.V.; Kiselev N.N.; Chub, E.V.; Mikryukova, T.P.; Protopopova, E.V.; Loktev, V.B.; Chumakov, P.M., Netesov, S.V. The Construction Of Recombinant Adenoviruses Expressing Apoptin. Vestnik of Tomsk State University. Biology. 2013, 3, 100-110. Russ.

82. Tkacheva, A.V.; Sivolobova, G.F.; Grazhdantseva, A.A.; Loktev, V.B.; Kochneva, G.V.; Shevelev, O.B.; Razumov, I.A.; Zavjalov, E.L. Targeted Therapy Of Human Glioblastoma Combining The Oncolytic Properties Of Parvovirus H-1 And Attenuated Strains Of The Vaccinia Virus. Molecular Genetics, Microbiology and Virology. 2019, 37, 140-147, doi:10.17116/molgen20193702183. Russ.

83. Kochneva, G.; Sivolobova, G.; Tkacheva, A.; Grazhdantseva, A.; Troitskaya, O.; Nushtaeva, A.; Tkachenko, A.; Kuligina, E.; Richter, V.; Koval, O. Engineering of Double Recombinant Vaccinia Virus with Enhanced Oncolytic Potential for Solid Tumor Virotherapy. Oncotarget 2016, 7, doi:10.18632/oncotarget.12367.

84. Stepanenko, A.A.; Chekhonin, V.P. Tropism and Transduction of Oncolytic Adenovirus 5 Vectors in Cancer Therapy: Focus on Fiber Chimerism and Mosaicism, Hexon and PIX. Virus Res 2018, 257, 40-51, doi:10.1016/j.virusres.2018.08.012.

85. Stepanenko, A.A.; Chekhonin, V.P. A Compendium of Adenovirus Genetic Modifications for Enhanced Replication, Oncolysis, and Tumor Immunosurveillance in Cancer Therapy. Gene 2018, 679, 11-18, doi:10.1016/j.gene.2018.08.069.

86. Logunov, D.Y.; Ilyinskaya, G.V.; Cherenova, L.V.; Verhovskaya, L.V.; Shmarov, M.M.; Chumakov, P.M.; Kopnin, B.P.; Naroditsky, B.S. Restoration of P53 Tumor-Suppressor Activity in Human Tumor Cells in Vitro and in Their Xenografts in Vivo by Recombinant Avian Adenovirus CELO-P53. Gene Ther 2004, 11, 79-84, doi:10.1038/sj.gt.3302146.

87. Reid, T.; Warren, R.; Kirn, D. Intravascular Adenoviral Agents in Cancer Patients: Lessons from Clinical Trials. Cancer Gene Ther 2002, 9, 979-986, doi:10.1038/sj.cgt.7700539.

88. Li, L.; Liu, S.; Han, D.; Tang, B.; Ma, J. Delivery and Biosafety of Oncolytic Virotherapy. Front Oncol 2020, 10, 475, doi:10.3389/fonc.2020.00475.

89. Chulpanova, D.S.; Solovyeva, V.V.; Kitaeva, K.V.; Dunham, S.P.; Khaiboullina, S.F.; Rizvanov, A.A. Recombinant Viruses for Cancer Therapy. Biomedicines 2018, 6, doi:10.3390/biomedicines6040094.

90. Kochneva, G.V.; Sivolobova, G.F.; Tkacheva, A.V.; Gorchakov, A.A. Kulemzin, S.V. Combined Therapy Of Cancer On The Basis Of Oncolytic Virotherapy And Targeted Car T/NK-Cell Immunotherapy. Molec Biol 2020, 54, doi:10.31857/S0026898420010103. Russ.

91. Berzhitskaya, D.; Chumakov, P. Dendritic Cells as Carriers of Oncolytic Viruses. Febs Open Bio 2019, 9.

92. Podshivalova, E.S.; Semkina, A.S.; Kravchenko, D.S.; Frolova, E.I.; Chumakov, S.P. Efficient Delivery of Oncolytic Enterovirus by Carrier Cell Line NK-92. Mol Ther Oncolytics 2021, 21, 110-118, doi:10.1016/j.omto.2021.03.013.

93. Vdovochenko, G.V.; Radaeva, I.F.; Sergeev, A.A.; Kolokol'tsova T.d.; Nechaeva, E.A.; Il'ina T.v.; Petrishchenko, V.A.; Ternovoy, V.A.; Sviatchenko, V.A.; Sergeev, A.N.; et al. Development of Banks of a 203-Cell Continuous Culture for Manufacturing the Anti-Tumor Therapeutic Preparation Cancerolysin. Biotechnology in Russia 2006. Russ.

94. Kasaraneni, N.; Chamoun-Emanuelli, A.M.; Wright, G.; Chen, Z. Retargeting Lentiviruses via SpyCatcher-SpyTag Chemistry for Gene Delivery into Specific Cell Types. mBio 2017, 8, doi:10.1128/mBio.01860-17.

95. Keeble, A.H.; Turkki, P.; Stokes, S.; Khairil Anuar, I.N.A.; Rahikainen, R.; Hytönen, V.P.; Howarth, M. Approaching Infinite Affinity through Engineering of Peptide-Protein Interaction. Proc Natl Acad Sci U S A 2019, doi:10.1073/pnas.1909653116.

96. Huang, L.-L.; Li, X.; Liu, K.; Zou, B.; Xie, H.-Y. Engineering Oncolytic Vaccinia Virus with Functional Peptides through Mild and Universal Strategy. Anal Bioanal Chem 2019, 411, 925-933, doi:10.1007/s00216-018-1519-3.

97. Cataldi, M.; Shah, N.R.; Felt, S.A.; Grdzelishvili, V.Z. Breaking Resistance of Pancreatic Cancer Cells to an Attenuated Vesicular Stomatitis Virus through a Novel Activity of IKK Inhibitor TPCA-1. Virology 2015, 485, 340-354, doi:10.1016/j.virol.2015.08.003.

98. Vandeborne, L.; Pantziarka, P.; Van Nuffel, A.M.T.; Bouche, G. Repurposing Infectious Diseases Vaccines Against Cancer. Front Oncol 2021, 11, 688755, doi:10.3389/fonc.2021.688755. 